\title{
COVID-19 internet vaccination information and vaccine administration: evidence from the United States
}

\author{
Rajeev K. Goel ${ }^{1,2}$ (D) Michael A. Nelson ${ }^{3}$ (D)
}

Accepted: 26 April 2021 /Published online: 3 June 2021

(c) Academy of Economics and Finance 2021

\begin{abstract}
This paper examines the impact of internet information on COVID-19 vaccination rates across U.S. states. Does greater information on the internet about COVID-19 vaccine access increase the number of vaccines administered? Does greater information about COVID-19 vaccine reliability facilitate vaccine administration? To gauge the COVID-19 related information on the world-wide-web we created two crossstate datasets using Google search. One search dealt with searching for information on vaccination availability and scheduling in each state, while the other search involved information on vaccine reliability and its side effects. The estimation results showed that greater availability of the relevant information on the internet increased vaccine administration rates, and this was true for both types of internet searches, resulting in an affirmative answer to the questions above. In contrast, the diffusion of internet access and the digital divide across states did not have a significant impact on vaccination rates. Whereas supply chain issues have garnered most of the attention in terms of the limitations of quickly vaccinating the public, our results show that internet information might be acting as a (largely unheralded) enabler.
\end{abstract}

Keywords COVID-19 $\cdot$ Coronavirus · Vaccine $\cdot$ Internet $\cdot$ Websites $\cdot$ Information dissemination · Vaccine administration · United States

JEL classification D11 $\cdot \mathrm{I} 18 \cdot \mathrm{K} 42$

\section{Introduction}

The fight against the COVID-19 pandemic has recently seen a glimmer of hope with the arrival and regulatory approval of a number of vaccines around the world.

Rajeev K. Goel

rkgoel@ilstu.edu

1 Department of Economics and Katie School of Insurance, Illinois State University, IL 61790-4200 Normal, USA

2 Kiel Institute for the World Economy, Kiel, Germany

3 University of Akron, Akron, $\mathrm{OH} 44325$, USA 
Many nations, especially wealthy nations, have started vaccinating their populations, using various guidelines to prioritize access to this scarce resource (Goel and Nelson 2021; Persad et al. 2020). Even within nations, such as states across the United States, regulations and vaccination delivery to populations vary. A common reason cited has been a lack of supply chain and administration logistics, coupled with the unique characteristics of some vaccines (e.g., short shelf life, transportation at certain temperatures, etc.) that has challenged the pace of vaccine delivery (Baldwin and Weder di Mauro 2020; Farzanegan et al. 2020; Goel et al. 2020, 2021). Yet, there are two sides to effective delivery and the demandside bottlenecks of vaccine delivery have been ignored. There have only been anecdotal pieces of evidence of eligible recipients not showing up for their vaccine appointments, leading to waste or arbitrary (out of turn) vaccinations.

The issue of lagging vaccine administration has profound implications for controlling the pandemic, saving lives, and return on public investments (since COVID-19 vaccine development was paid for by taxpayer dollars in the United States). ${ }^{1}$ This paper tries to address the shortcomings on demand-side vaccination bottlenecks by examining the role of the internet. In general, the internet has been a game-changer in many markets, impacting the demand and supply not only of information but also related transaction costs (see Goel and Hsieh 2002). The internet is being used as a key, often primary, means to provide information about the coronavirus, vaccine availability and safety information, and information about the scheduling and delivery (the last mile of the vaccination process).

Two unique questions addressed in this research are:

- Does greater information on the internet about COVID-19 vaccine access increase the number of vaccines administered?

- Does greater information about COVID-19 vaccine reliability facilitate vaccine administration?

To address these questions, we use internet search results (total number of search hits) on Google across U.S. states for a recent month (February 2021), with the following alternative keywords:

(a) search A (vaccine access search): "state name COVID-19 vaccine coronavirus appointment schedule location provider", with "COVID-19 vaccine" being the exact phrase in the search

(b) search B (vaccine reliability search): "state name COVID-19 coronavirus adverse health effects vaccine side illness", with "COVID-19" being the exact phrase in the search.

These searches capture the relevant information available on the internet regarding the availability and reliability of coronavirus vaccines. Since Google's search

\footnotetext{
1 See https://www.brookings.edu/blog/fixgov/2021/02/02/whats-the-hold-up-why-more-vaccines-haventbeen-administered/
} 
algorithm lists the sites most accessed first, ${ }^{2}$ there is some inherent quality distinction in the searches (also see appendices A and B). These internet searches yielded information by government agencies, public health groups, international organizations, industry groups (health and insurance providers), special interest groups, etc. Appendices A and B show the top 25 hits for searches A and B, respectively. Although the searches yielded hundreds of thousands of hits (see Table 1), the samples of top search hits in both cases show useful and pertinent information that would empower potential consumers and seekers of vaccines.

Since internet search results can change rapidly, all the searchers for a set of keywords were done in a single sitting, i.e., 2-3 hour window with no breaks in the last week of February 2021 (Search B) and the first week of March 2021 (Search A).

With some similarities in the names of some states, a couple of adjustments were made to avoid double-counting. These included: (i) in the case of the state of Virginia, taking out the word "West" to exclude sites with West Virginia; and (ii) in the case of the state of Washington, excluding the words "DC" and "District of Columbia" to avoid overlap with Washington, DC.

In spite of these refinements and the case about the timing of searches, internet searching remains imperfect, especially for the general public and non-computer specialists. For example, there could be mirror sites where the same information is displayed on multiple sites (hosted by the same or different organizations), fake sites selling dubious products with text/title relevant to coronavirus to generate hits/traffic, etc. Nevertheless, the application of internet searches to gauge information/awareness used in this paper is novel in the context of coronavirus vaccines. This methodology, however, has been successfully used in other contexts (Goel et al. 2012; Goel and Nelson 2014). One of the first applications in economics was by Goel et al. (2012) to measure cross-country corruption awareness. Thankfully, the language disparities experienced across different nations are less of an issue when searching across states in the United States (also see Section 3.3 for a consideration of the language aspect). ${ }^{3}$

The estimation results showed that greater availability of the relevant information on the internet increased vaccine administration rates, and this was true for both types of internet searches. In contrast, the diffusion of internet access and the digital divide across states did not have a significant impact on vaccination rates.

The structure of the rest of the paper includes the model and data in the next section, followed by results and conclusions.

\footnotetext{
2 https://www.google.com/search/howsearchworks/algorithms/

${ }^{3}$ Furthermore, in recent years Google has become the leading search engine, whereas Goel et al. (2012) also performed a comparable search in Yahoo as a robustness check. In any case, Google's search algorithm, based on the quality of searches remains relatively superior (https://www.google.com/search/ howsearchworks/algorithms/).
} 


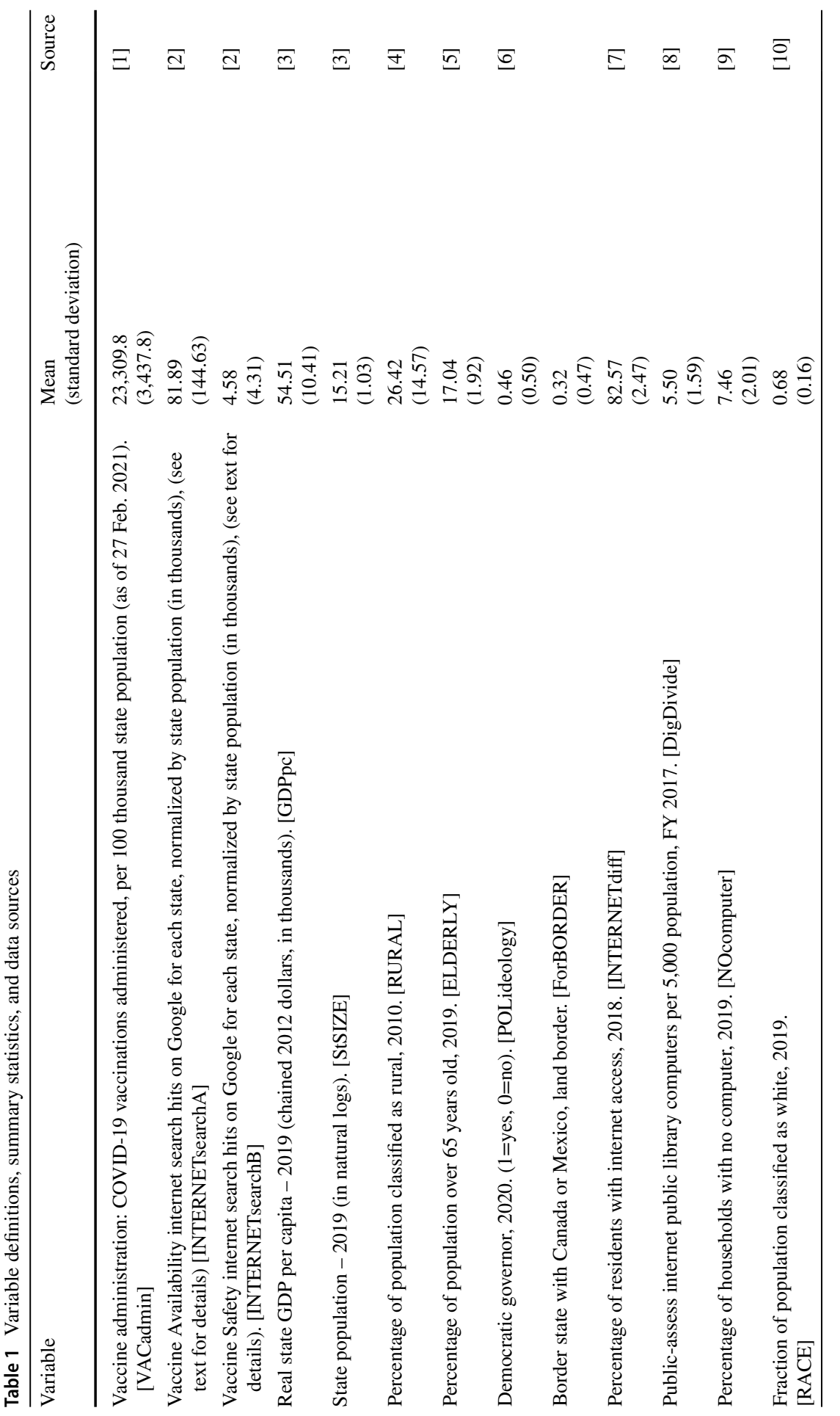




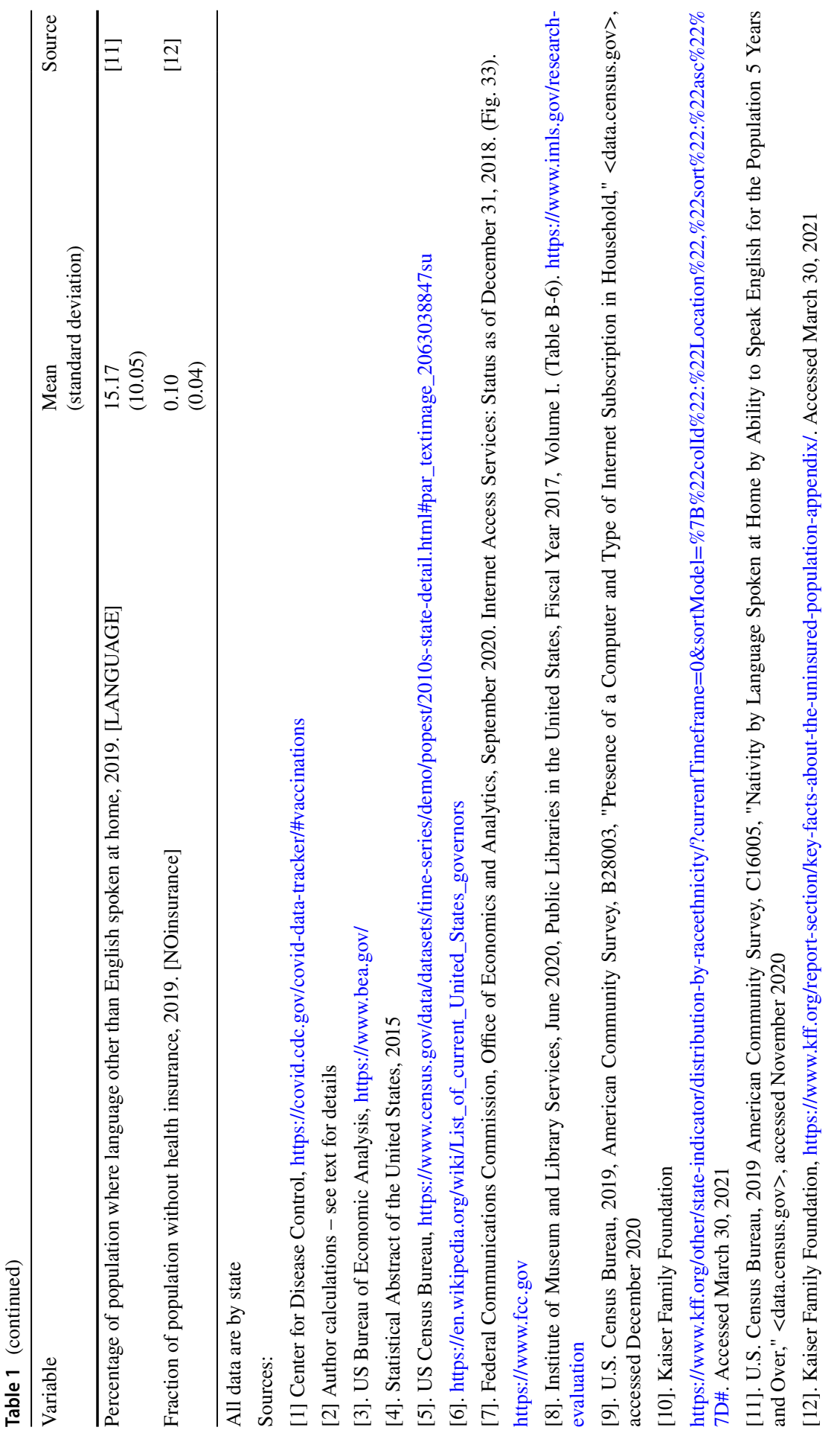




\section{Empirical model and data}

\subsection{Model}

Based on the above discussion, we formulate our main hypothesis that we will test formally using an econometric model that follows:

Hypothesis: Greater internet information on vaccine access and reliability will facilitate COVID-19 vaccine administration, ceteris paribus.

As discussed above, greater information on the internet about the availability, reliability, and scheduling of coronavirus vaccines would lower transactions costs, mitigate perceived risks and lead to more vaccines being administered.

The general form of the estimated equation is the following (with the unit of observation being a state in the United States):

VACadmin $=\mathrm{f}($ INTERNETinfoi, INTERNETdiff, DigDivide, Zj)

$$
\begin{aligned}
\mathrm{i}= & \text { INTERNETsearchA, INTERNETsearchB } \\
\mathrm{j}= & \text { GDPpc, RURAL, ELDERLY, RACE, LANGUAGE, } \\
& \text { NOinsurance, StSIZE, ForBORDER, POLideology }
\end{aligned}
$$

The dependent variable is the COVID-19 vaccines administered in a state in the United States as of February 27, 2021. As of that date, the average VACadmin was 23,310 doses per 100,000 population across the 50 states. These could be the first doses of the Pfizer or the Moderna vaccine. ${ }^{4}$ States have different rules for prioritizing vaccinations and some of the doses administered might be to non-residents. For example, there are reports of vaccine tourism from Florida. Although the related numbers are changing every week (day), there remains considerable vaccine administration variation across states, even in per capita terms - the range being 18,606 to 35,478.

The novel angle here is the consideration of the internet information available across two qualitatively different dimensions (INTERNETsearchA and INTERNETsearchB) using Google (see Section 1 above). Greater information about vaccine availability and safety is likely to facilitate vaccine administration. This might involve more residents seeking appointments either through greater confidence in vaccines or lower transaction costs of acquiring information and of scheduling vaccinations. The signs and statistical significance of the estimated coefficients on INTERNETsearchA and INTERNETsearchB will test the validity of the hypothesis posed above.

\footnotetext{
${ }^{4}$ As the reader would notice, the doses administered would be lower than the vaccine doses delivered to each state due to wastage, logistical factors, mismanagement, and spoilage (see Goel and Nelson 2021).
} 
The correlation between INTERNETsearchA and INTERNETsearchB in our sample was 0.30 . Furthermore, the correlation between VACadmin and INTERNETsearchA was 0.38, and that between VACadmin and INTERNETsearchB was 0.69.

Digital divide (DigDivide), households without computers (NOcomputer), and internet diffusion (INTERNETdiff) are included to account for the ability to access (and sometimes produce) information on the internet. Even within a prosperous nation like the United States, there is variation across states in the ability of residents to access the internet, although some of these differences are being reduced with the prevalence of smartphones.

The vector $\mathrm{Z}$ includes a set of state-level social, economic, political, and geographic factors that are likely to impact the administration of COVID-19 vaccines. GDPpc captures state economic prosperity - wealthier states, ceteris paribus, would have better infrastructures to administer vaccines, whereas state size (StSIZE), measured via state population, could have the opposite effect. State size (StSIZE) accounts for scaling and logistical challenges with efficiently vaccinating the populations in larger, more populous states - https://www.yesmagazine.org/ health-happiness/2021/02/17/covid-vaccine-rollout-united-states/.

RURAL and ELDERLY capture the social dimensions associated with the challenges of vaccine administration. States with a larger percentage of the rural population would likely face greater challenges providing information and administration of vaccines to the rural population. Most states have been following federal Centers for Disease Control and Prevention (CDC) guidelines and prioritizing senior citizens to get the vaccines, and given the timing of our administration data, states with a greater share of the elderly would show greater vaccine administrations, ceteris paribus. ${ }^{5}$ Two additional social dimensions that we considered dealt with race (RACE) and English language communication skills (LANGUAGE) as they can also impact propensities to seek vaccinations.

The political ideology of state governors might matter in a state's approach toward combating the pandemic. Accordingly, we include POLideology to identify states with a Democratic governor (see Potrafke (2018) for a review of the literature on the role of political ideology in economics research). ${ }^{6}$

Finally, geographic aspects are considered by including a dummy variable, ForBORDER, to identify states bordering Canada or Mexico. ${ }^{7}$ The logic is that, other things being equal, residents in these states might either have different attitudes towards vaccinations or such states might have a larger share of casual foreign visitors, even during the pandemic travel restrictions. Next, the data used to estimate Eq. (1) is discussed.

\footnotetext{
${ }^{5}$ However, there are reports of mismanagement in getting the vaccines to the elderly - https://fox $59 . \mathrm{com} /$ news/falling-through-cracks-vaccine-bypasses-some-older-adults/

${ }^{6}$ Along a related dimension, we also considered the democratic vote share in the last presidential election (see footnote 12).

${ }^{7}$ Although technically not bordering a foreign nation, we also included Hawaii in this group, since Hawaii is different from the 48 -contiguous states.
} 


\subsection{Data}

Data on the number of COVID-19 vaccine doses administered are taken from the Centers for Disease Control and Prevention (CDC) COVID Tracker website. ${ }^{8}$ State-level tracking began on December 14, 2020, about the time initial vaccine shipments began to roll out to the states and are updated daily based on data reported by the individual states. At the time of writing, the most recent data on state vaccination administration was for February 27, 2021, and that is what is used in this analysis. By that date, most states were still at the Phase $1 \mathrm{~b}$ priority group for vaccine distribution, with those that followed the CDC Advisory Committee on Immunization Practices (ACIP) recommendations now vaccinating persons 75 years and older. ${ }^{9}$ Thirteen states had even progressed to Priority group 1c. All states included some seniors in the eligibility group, although the minimum age varied from 65 years old to 75 depending upon the state. ${ }^{10}$ As of the data considered in this analysis, the number of total doses administered per 100,000 population in a state ranged from a low of 18,606 in Texas to a high of 35,478 in Alaska, with a mean value of 23,320 doses across all the states.

The two internet search variables used in this analysis (INTERNETsearchA and INTERNETsearchB) were calculated by the authors using the process described in the introduction of this paper. In both cases, total search results for each state were normalized by state population (measured in thousands). Results showed a large variation across the 50 states for each measure. This variation is shown in Fig. 1 (vaccine availability) and Fig. 2 (vaccine safety) where the normalized search results for the ten highest states and the bottom ten states are depicted along with the sample mean for all 50 states. While there is some consistency in the names of the top (bottom) states depicted in the two figures, some important differences stand out (e.g., Virginia - the state at the bottom in Fig. 1 is not even among the bottom ten in Fig. 2). Overall, the correlation between these two search measures is only 0.29 in our sample, indicating that there are some important differences between these two in terms of the information conveyed.

Internet access (INTERNETdiff) is measured by the percentage of residents in a state that have access to the internet in 2018, the most recent year with available data. To gauge the significance of the digital divide across the states (DigDivide) we use the number of public-access (library) internet computers per 5,000 per state residents in 2017 , the most recent year available. The correlation coefficient between these two measures of internet access in our data set is -0.46 .

Data for the control variables used in this analysis are drawn from reliable sources regularly used in literature. Further details on all on the other variables used in the analysis, descriptive statistics, and data sources can be found in Table 1 . The results section follows.

\footnotetext{
${ }^{8}$ https://covid.cdc.gov/covid-data-tracker/\#vaccinations

${ }^{9}$ https://www.cdc.gov/vaccines/hcp/acip-recs/vacc-specific/covid-19.html

10 https://www.kff.org/other/state-indicator/state-covid-19-vaccine-priority-populations/
} 


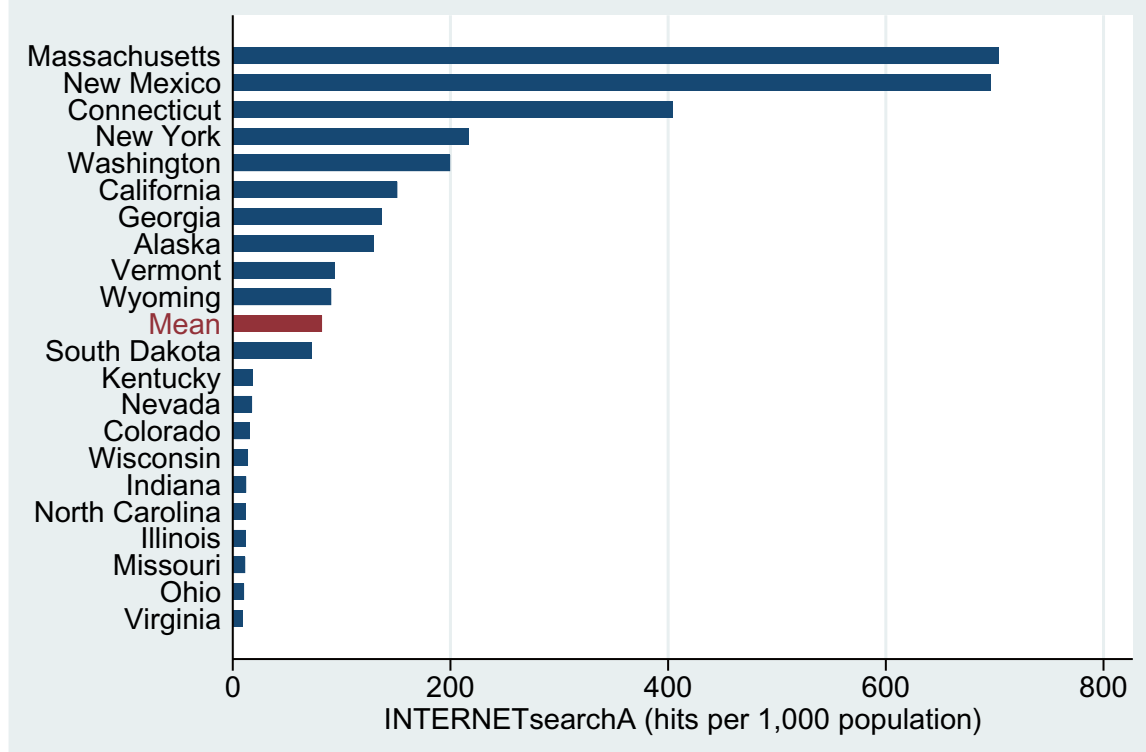

Fig. 1 Vaccine availability and scheduling internet hits

\section{Results}

We estimate two sets of models representing equation (1), one set including the internet search information variables, and a second set including both internet search and internet diffusion/digital divide measures. Results are summarized in Tables 2 and 3 , respectively.

\subsection{Drivers of COVID-19 vaccine administration using search information on vaccine access and reliability}

Models 2.1 through 2.3 in Table 2 report the results when the vaccine availability [INTERNETsearchA] is used as a right-hand-side regressor. The models vary only in terms of whether foreign border (ForBORDER) or Democratic governor (POLideology) is included as an additional control variable in the regression setup.

In each of the three models, there is strong statistical support for the proposition that information on vaccine availability, as measured by our internet search variable, positively affects the number of doses of COVID-19 state vaccinations, other things being equal. In each model, the parameter estimate on the internet search variable is statistically significant at better than the 5 percent level of confidence. Greater vaccine availability and scheduling information on the internet lowers the transaction or information costs for the public and this improves vaccination rates. 


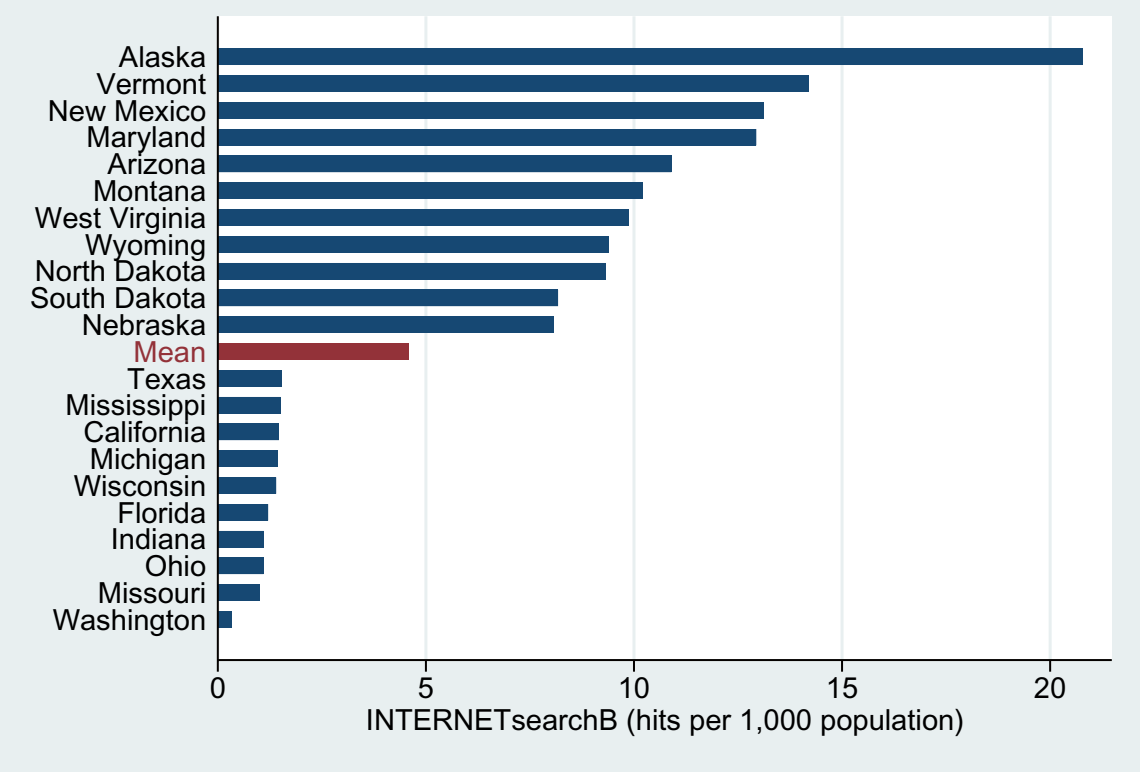

Fig. 2 Vaccine safety and reliability internet hits

This happens by, for example, greater number of vaccine recipients showing up (and showing up promptly) for vaccine appointments, and fewer no-shows (that are especially important in this context as the vaccines have a short shelf life). It could also be the case that the relevant internet information provides useful signals to suppliers and improves supply chain performance, yielding greater vaccination rates.

The parameter estimates on the INTERNETsearchA variable are quite consistent across the three models estimated. This finding supports our main hypothesis. In terms of the actual impact of the search variable on vaccine administration, the parameter estimate on INTERNETsearchA in Model 2.1 (8.07) implies that if internet searches for a state were to increase by one standard deviation based on our data set (144.6 - see Table 1) this would lead to an increase of approximately 1,200 doses administered. That figure represents approximately one-third of the sample standard deviation of state vaccines administered in our data set.

Of all the control variables considered in these models, only state size (StSIZE), as measured by its population, is statistically significant at conventional levels. This result indicates that smaller states seem to be more adept at vaccinating their populations. Based on the parameter estimates on the state size variable in Models 2.12.3 , the results suggest that a one standard deviation in state population - as defined in this analysis - will translate into approximately 2,000 fewer vaccinations per 100,000 state population. 
Table 2 Vaccine administration: Internet information on COVID-19 vaccine access and reliability

\begin{tabular}{|c|c|c|c|c|c|c|}
\hline Model $\rightarrow$ & 2.1 & 2.2 & 2.3 & 2.4 & 2.5 & 2.6 \\
\hline \multicolumn{7}{|c|}{ Internet search information variable } \\
\hline Vaccine Availability & $8.07^{* *}$ & $7.70^{* *}$ & $8.16^{* *}$ & & & \\
\hline [INTERNETsearchA] & $(2.1)$ & $(2.3)$ & $(2.3)$ & & & \\
\hline Vaccine Safety & & & & $404.49^{* *}$ & $388.88^{* *}$ & $460.72^{* * *}$ \\
\hline [INTERNETsearchB] & & & & $(2.6)$ & $(2.5)$ & $(3.0)$ \\
\hline \multicolumn{7}{|c|}{ Other state-level control variables } \\
\hline State Per Capita GDP & 66.30 & 54.96 & 62.89 & $74.03^{*}$ & $68.86^{*}$ & 58.47 \\
\hline [GDPpc] & $(1.3)$ & $(1.1)$ & $(1.2)$ & $(1.9)$ & $(1.7)$ & $(1.5)$ \\
\hline State Population & $-1,753.1^{* *}$ & $-1,743.7^{* *}$ & $-1,769.7^{* *}$ & -771.1 & $-805.3^{*}$ & -691.5 \\
\hline [StSIZE] & $(3.8)$ & $(3.9)$ & $(3.8)$ & $(1.6)$ & $(1.7)$ & $(1.4)$ \\
\hline Percent of Population $>65$ & 12.54 & -2.66 & -13.60 & 172.82 & 161.04 & 87.21 \\
\hline [ELDERLY] & $(0.0)$ & $(0.0)$ & $(0.0)$ & $(0.9)$ & $(0.8)$ & $(0.4)$ \\
\hline Rural Population & 27.18 & 20.81 & 31.08 & 11.64 & 8.95 & 24.98 \\
\hline [RURAL] & $(0.8)$ & $(0.7)$ & $(0.9)$ & $(0.4)$ & $(0.3)$ & $(0.8)$ \\
\hline Foreign Border State & & 925.78 & & & 453.47 & \\
\hline [ForBORDER] & & $(1.1)$ & & & $(1.1)$ & \\
\hline Democratic Governor & & & 341.25 & & & $1,270.5^{*}$ \\
\hline [POLideology] & & & $(0.4)$ & & & $(1.7)$ \\
\hline Adj. R-Squared & 0.44 & 0.44 & 0.43 & 0.50 & 0.49 & 0.52 \\
\hline F-statistic & $6.72^{* *}$ & $6.06^{* *}$ & $5.72^{* *}$ & $6.95^{* *}$ & $5.95^{* *}$ & $5.92^{* *}$ \\
\hline Observations & 50 & 50 & 50 & 50 & 50 & 50 \\
\hline
\end{tabular}

Variable definitions are provided in Table 1. All models are estimated via ordinary least squares and include a constant term (not reported). The numbers in parentheses are robust (absolute value) t-statistics *denotes statistical significance at the $10 \%$ level; **denotes significance at the $5 \%$ level (or better)

In other results, states with a greater proportion of the elderly or rural populations, and states bordering Canada and Mexico were no different from other states in terms of vaccination rates. This insignificance also holds for GDPpc and POLideology in Models 2.1-2.3. ${ }^{11}$

Turning to vaccine reliability, Models 2.4 through 2.6 in Table 2 report the results when vaccine safety [INTERNETsearchB] is used as a right-hand-side regressor. Similar to the vaccine availability search variable, the parameter estimate on this variable is positive and statistically significant across all three models where it is used. Again, these results lend support to our main hypothesis. INTERNETsearchB is qualitatively different from INTERNETsearchA as it addresses inherent risk aversion. Greater information about the vaccine reliability enables more people to go out and seek vaccines, ceteris paribus.

Moreover, the actual impact of this variable appears to be greater than it is for the vaccine availability measure. For example, the parameter estimate on

\footnotetext{
11 When state poverty rate was used in the place of GDPpc, the resulting coefficient on poverty remained statistically insignificant. Furthermore, the addition of state unemployment rate as a regressor showed the coefficient on unemployment to be insignificant. These results are available upon request.
} 
INTERNETsearchB in Model 2.4 (404.49) implies that if internet safety searches for a state were to increase by one standard deviation based on our data set (4.31 - see Table 1) this would lead to an increase of approximately 1,700 doses administered. This represents approximately one-half of the sample standard deviation of the VACadmin variable. Similar results were obtained using the parameter estimates on the search variable in Models 2.5 and 2.6.

In terms of the control variables used in Models 2.4-2.6, relative to the first three models considered in Table 2, there is somewhat less statistical support for the proposition that state size (population) is an important driver of the number of vaccines administered. However, there is more support for the proposition that state economic prosperity (GDPpc) enhances a state's record in this regard. Again, ELDERLY and RURAL failed to attain statistical significance. Finally, states with a Democratic governor (Model 2.6) appear to have a better record when it comes to the vaccine rollout, at least for the dates considered in this analysis. ${ }^{12}$

Overall, all six models summarized in Table 2 perform well, when judged by R-square and consistently statistically significant F-statistic reported towards the bottom of the table. Next, we consider an extension by addressing dimensions of the public's ability to access the internet.

\subsection{Additional consideration 1: impact of internet diffusion and the digital divide}

Table 3 takes account of the diffusion of the internet (via the population with internet access (INTERNETdiff)), and the digital divide (proxied by the public access public library internet computers per 5,000 population (DigDivide)). These variables can be seen as capturing the demand side of internet information, although some of the folks with internet access would also be producers of internet information (by, for example, generating/maintaining/authoring websites). In our sample, more than 82 percent of residents in the US had internet access, and there were about 6 public access internet computers on average per public library. The correlation between INTERNETdiff and DigDivide was -0.47 ; consistent with the intuition that greater internet diffusion reduced the need for public access computers.

When INTERNETdiff and DigDivide were alternately added to variants of baseline models from Table 2, the results in Table 3 show that the signs on the two variables differ: the coefficient on INTERNETdiff is positive, while that on DigDivide is negative. However, in both cases, the relevant coefficients failed to attain statistical significance.

The results with regard to the positive and statistically significant effects of the two internet search variables (INTERNETsearchA and INTERNETsearchB) reinforced earlier findings. Thus, it is not the access to the internet, per se, but the quantity and quality of the relevant information available on the internet that facilitates the administration of the COVID-19 vaccines.

\footnotetext{
12 As an alternative consideration of the political factors, we considered the state-level Democratic vote share in the 2020 presidential election. The resulting coefficient on the vote share variable was statistically insignificant in both cases. These results are not reported but are available upon request.
} 
The other results support what was reported earlier - larger states face vaccine administration challenges, while more prosperous states had vaccine administration advantages, especially when INTERNETsearchB was considered (Models 3.2 and 3.5).

Along another related dimension of the digital divide, we considered the percent of state households without a computer (NOcomputer). The corresponding results, in Models 3.3 and 3.6 in Table 3, showed that NOcomputer lacked statistical significance. In the following section, we consider some additional dimensions that might impact vaccinations.

Table 3 Vaccine administration: Internet information on COVID-19, internet diffusion and the digital divide

\begin{tabular}{|c|c|c|c|c|c|c|}
\hline \multicolumn{7}{|c|}{ Dependent variable: Vaccines administered per 100k population [VACadmin] } \\
\hline Model $\rightarrow$ & 3.1 & 3.2 & 3.3 & 3.4 & 3.5 & 3.6 \\
\hline \multicolumn{7}{|c|}{ Internet search information variable } \\
\hline Vaccine Availability & $7.70^{* *}$ & & $7.98^{* *}$ & $8.12^{* *}$ & & \\
\hline [INTERNETsearchA] & $(2.0)$ & & $(2.1)$ & $(2.1)$ & & \\
\hline Vaccine Safety & & $385.65^{* *}$ & & & $379.60^{* *}$ & $409.09^{* *}$ \\
\hline [INTERNETsearchB] & & $(2.5)$ & & & $(2.6)$ & $(2.7)$ \\
\hline \multicolumn{7}{|c|}{ Internet diffusion and digital divide } \\
\hline Residential Internet Access & 231.42 & 142.47 & & & & \\
\hline [INTERNETdiff] & $(0.9)$ & $(0.7)$ & & & & \\
\hline Public Access Internet & & & & -261.83 & -261.62 & \\
\hline [DigDivide] & & & & $(1.1)$ & $(1.2)$ & \\
\hline Households with no computer & & & -2.93 & & & 266.80 \\
\hline [NOcomputer] & & & $(0.0)$ & & & $(1.1)$ \\
\hline \multicolumn{7}{|l|}{ Other state-level control variables } \\
\hline State Per Capita GDP & 76.74 & $80.88^{* *}$ & 66.11 & 75.86 & $83.72^{* *}$ & $86.46^{* *}$ \\
\hline [GDPpc] & $(1.5)$ & $(2.1)$ & $(1.3)$ & $(1.4)$ & $(2.1)$ & $(2.4)$ \\
\hline State Population & $-1,769.7^{* *}$ & $-828.1^{*}$ & $-1,751.5^{* *}$ & $-1,868.9^{* *}$ & $-882.9^{*}$ & $-893.8^{*}$ \\
\hline [StSIZE] & $(4.0)$ & $(1.7)$ & $(3.7)$ & $(4.0)$ & $(1.8)$ & $(1.8)$ \\
\hline Percent of Population $>65$ & 59.59 & 196.44 & -12.88 & 10.87 & 172.12 & 128.51 \\
\hline [ELDERLY] & $(0.2)$ & $(1.1)$ & $(0.1)$ & $(0.0)$ & $(0.9)$ & $(0.6)$ \\
\hline Rural Population & 49.33 & 25.80 & 27.40 & 39.05 & 23.40 & -6.99 \\
\hline [RURAL] & $(1.1)$ & $(0.8)$ & $(0.8)$ & $(1.0)$ & $(0.7)$ & $(0.2)$ \\
\hline Adj. R-square & 0.44 & 0.50 & 0.42 & 0.43 & 0.50 & 0.50 \\
\hline F-statistic & $5.94^{* *}$ & $6.15^{* *}$ & $5.71^{* *}$ & $5.82^{* *}$ & $6.36^{* *}$ & $6.16^{* *}$ \\
\hline Observations & 50 & 50 & 50 & 50 & 50 & 50 \\
\hline
\end{tabular}

Variable definitions are provided in Table 1 . All models are estimated via ordinary least squares and include a constant term (not reported). The numbers in parentheses are robust (absolute value) t-statistics *denotes statistical significance at the $10 \%$ level; **denotes significance at the $5 \%$ level (or better) 


\subsection{Additional consideration 2: accounting for social and insurance factors}

The demand for vaccinations might be influenced by other social and insurance factors. Accordingly, we consider three dimensions: (a) RACE - the percent of population in a state that is white; (b) LANGUAGE - percent of the population that speaks a language other than English at home; and (c) NOinsurance - percent of state population without health insurance. The race could affect attitudes towards vaccinations, while language captures the ability of pro- and anti-vaccination campaigns to reach certain populations. Furthermore, while in general a lack of health insurance would adversely affect vaccinations, COVID-19 vaccines are being dispensed free of charge in the United States because vaccine development was heavily underwritten by taxpayer dollars.

Adding these three factors, respectively, as regressors to baseline models from Table 2, we report these results in Table 6 in the Appendix C. The results show that the coefficients on RACE and NOinsurance were statistically insignificant in all cases, while LANGUAGE is marginally significant at the $10 \%$ level in Model A.2, but insignificant in Model A.5. More importantly, the main internet control variables, INTERNETsearchA and INTERNETsearchB, remain positive and statistically significant in all cases. This lends further support to the main findings of the paper. The concluding section follows.

\section{Concluding remarks}

The global fight against the coronavirus appears to be in the final stages in the US (notwithstanding the recent virus variants), with the availability of several vaccines. However, the speed of the vaccination rollout drives has been a source of frustration with the public and policymakers, with supply-chain issues (especially given the peculiar storage and transportation requirements of some vaccines) frequently cited as a key underlying constraint (also see, Goel et al. 2020, 2021; Kaur and Gupta 2020). The role of potentially mitigating forces, such as the internet, has not been formally considered. The internet can lower information and transaction costs resulting in lower vaccine risk perceptions and greater/more-efficient scheduling of vaccine appointments.

To address formally the role of the internet in the vaccination process, this paper uniquely examines the impact of internet information on COVID-19 vaccination rates across U.S. states. Despite the recent nature of the coronavirus, some formal research has emerged focusing on different aspects of the pandemic (see Alfano and Ercolano 2020; Asongu et al. 2020; Bayram and Shields 2021; Farzanegan et al. 2020; Goel and Nelson 2021; Price and van Holm 2021; Yum 2020; Baldwin and Weder di Mauro 2020) for a broader review). However, the role of the internet, in terms of the information related to COVID-19 vaccines available on websites, considered in this paper is new.

To gauge the COVID-19 related information on the world-wide-web we created two cross-state datasets using Google search. One search dealt with searching 
for information on vaccination availability and scheduling in each state (INTERNETsearchA), while the other search involved information on vaccine reliability and its side effects (INTERNETsearchB). Some refinements were performed to sanitize the search results from unnecessary noise and avoid double-counting.

The estimation results showed that greater availability of the relevant information on the internet increased vaccine administration rates, and this was true for both types of internet searches. This answers the two questions posed in the Introduction and is consistent with the notion of lower transaction costs via easier access to the related health information on the internet and greater ease of scheduling vaccination appointments. In terms of relative magnitudes, the elasticity of vaccine administrations with respect to internet vaccine reliability information (INTERNETsearchB) was almost three times as large as that with respect to internet vaccine scheduling and availability information (INTERNETsearchA), specifically, Model 2.1: $\varepsilon_{\text {VACadmin,INTERNETsearchA }}=0.03$; and Model 2.4: $\varepsilon_{\mathrm{VACadmin,INTERNETsearchB}}=0.08$. In other words, the risk-reduction role of internet searches yield greater vaccination returns compared to its scheduling role, although both are positive. The relatively modest size of the two elasticities makes sense when one thinks about the large magnitude of internet hits. Plus, effectively consumers and potential consumers would likely be looking at the top search hits most of the time and their responses are less likely to be driven by how search results are populated at the lower end of the search distribution (See appendices $\mathrm{A}$ and $\mathrm{B}$ ).

In contrast, the diffusion of internet access and the digital divide across states did not have a significant impact on vaccination rates. Thus, it is not the access to the internet per se but the information available on the internet that enables vaccinations. The findings about the efficacy of internet information can be seen as complementary to the literature that focuses on the effectiveness of digital tracking in controlling the spread of the virus (see Abdou 2021).

Whereas supply chain issues have garnered most of the attention in terms of the limitations of quickly vaccinating the public, our results show that internet information might be acting as a (largely unheralded) enabler. Greater efforts by policymakers, either directly or by subsidizing related websites would assist in vaccinations and ultimately in controlling the virus. The results are also instructive for industry groups like health and liability insurance companies since internet outreach seems effective in facilitating vaccinations and ultimately reducing insurance costs.

\section{Appendix A}

\section{Top 25 Google search hits (INTERNETsearchA)}

(See Table 4) 
Table 4 Search keywords: "Covid-19 vaccine" coronavirus appointment schedule location provider

\begin{tabular}{|c|c|c|c|}
\hline Hit number & Site type & Topic & Additional information \\
\hline 1 & CDC & Vaccine Finder website & $\begin{array}{l}\text { Helps people find information } \\
\text { about providers }\end{array}$ \\
\hline 2 & State government & $\begin{array}{l}\text { Information on vaccine availability \& } \\
\text { scheduling }\end{array}$ & Connecticut \\
\hline 3 & $\begin{array}{l}\text { Non-profit health } \\
\text { care org }\end{array}$ & $\begin{array}{l}\text { Information on vaccine availability \& } \\
\text { scheduling }\end{array}$ & $\begin{array}{l}\text { Focus is on Washington State } \\
\text { (MultiCare organization) }\end{array}$ \\
\hline 4 & State government & $\begin{array}{l}\text { Information on vaccine availability \& } \\
\text { scheduling }\end{array}$ & California \\
\hline 5 & State government & $\begin{array}{l}\text { Information on vaccine availability \& } \\
\text { scheduling }\end{array}$ & Texas \\
\hline 6 & State government & $\begin{array}{l}\text { Information on vaccine availability \& } \\
\text { scheduling }\end{array}$ & New York \\
\hline 7 & County government & $\begin{array}{l}\text { Information on vaccine availability \& } \\
\text { scheduling }\end{array}$ & Maricopa County, AZ \\
\hline 8 & County government & $\begin{array}{l}\text { Information on vaccine availability \& } \\
\text { scheduling }\end{array}$ & Tri-county County Colorado \\
\hline 9 & County government & $\begin{array}{l}\text { Information on vaccine availability \& } \\
\text { scheduling }\end{array}$ & Santa Clara County CA \\
\hline 10 & Health care org & $\begin{array}{l}\text { Information on vaccine availability \& } \\
\text { scheduling }\end{array}$ & University Health TX \\
\hline 11 & Health care org & $\begin{array}{l}\text { Information on vaccine availability \& } \\
\text { scheduling }\end{array}$ & $\begin{array}{l}\text { Vaccine Finder - helps with sched- } \\
\text { uling appointments nationally }\end{array}$ \\
\hline 12 & Government & $\begin{array}{l}\text { Information on vaccine availability \& } \\
\text { scheduling }\end{array}$ & District of Columbia \\
\hline 13 & State government & $\begin{array}{l}\text { Information on vaccine availability \& } \\
\text { scheduling }\end{array}$ & Alaska \\
\hline 14 & Health care org & $\begin{array}{l}\text { Information on vaccine availability \& } \\
\text { scheduling }\end{array}$ & $\begin{array}{l}\text { University of Colorado Health } \\
\text { Care System }\end{array}$ \\
\hline 15 & Health care org & $\begin{array}{l}\text { Information on vaccine availability \& } \\
\text { scheduling }\end{array}$ & $\begin{array}{l}\text { Beaumont Health System - } \\
\text { Michigan }\end{array}$ \\
\hline 16 & Health care org & $\begin{array}{l}\text { Information on vaccine availability \& } \\
\text { scheduling }\end{array}$ & $\begin{array}{l}\text { UC Davis Health Care System - } \\
\text { California }\end{array}$ \\
\hline 17 & Health care org & $\begin{array}{l}\text { Information on vaccine availability \& } \\
\text { scheduling }\end{array}$ & $\begin{array}{l}\text { Huntington Hospital located in } \\
\text { LA county, California }\end{array}$ \\
\hline 18 & State government & $\begin{array}{l}\text { Information on vaccine availability \& } \\
\text { scheduling }\end{array}$ & South Carolina \\
\hline 19 & Health care org & $\begin{array}{l}\text { Information on vaccine availability \& } \\
\text { scheduling }\end{array}$ & $\begin{array}{l}\text { Atlantic Health Care Organization } \\
(\mathrm{NY}, \mathrm{PA}, \mathrm{NJ})\end{array}$ \\
\hline 20 & Health care org & $\begin{array}{l}\text { Information on vaccine availability \& } \\
\text { scheduling }\end{array}$ & $\begin{array}{l}\text { University of California San } \\
\text { Diego Health }\end{array}$ \\
\hline 21 & Health care org & $\begin{array}{l}\text { Information on vaccine availability \& } \\
\text { scheduling }\end{array}$ & $\begin{array}{l}\text { Mt. Carmel Health Columbus } \\
\text { Ohio }\end{array}$ \\
\hline 22 & State government & $\begin{array}{l}\text { Information on vaccine availability \& } \\
\text { scheduling }\end{array}$ & Mississippi \\
\hline 23 & Health care org & $\begin{array}{l}\text { Information on vaccine availability \& } \\
\text { scheduling }\end{array}$ & $\begin{array}{l}\text { TriHealth serving SE Ohio } \\
\text { (Cincinnati) }\end{array}$ \\
\hline
\end{tabular}


Table 4 (continued)

\begin{tabular}{llll}
\hline Hit number & Site type & Topic & Additional information \\
\hline 24 & County government & $\begin{array}{c}\text { Information on vaccine availability \& } \\
\text { scheduling }\end{array}$ & DeKalb County, IL \\
25 & Health care org & $\begin{array}{c}\text { Information on vaccine availability \& } \\
\text { scheduling }\end{array}$ & Univ. of Miami (Florida) \\
\hline
\end{tabular}

Search conducted: March 6, 2021, 1600 CST; Org organization

\title{
APPENDIX B
}

\section{Top 25 Google search hits (INTERNETsearchB)}

\author{
(See Table 5)
}

Table 5 Search keywords: "Covid-19" coronavirus adverse health effects vaccine side illness

\begin{tabular}{|c|c|c|c|}
\hline Hit number & Site type & topic & Additional information \\
\hline 1 & Medical School & Vaccine side effects & Harvard Health Publishing \\
\hline 2 & $\mathrm{CDC}$ & Vaccine side effects & \\
\hline 3 & $\mathrm{CDC}$ & Vaccine side effects & \\
\hline 4 & WHO & Vaccine FAQ & \\
\hline 5 & Health News Website & Vaccine side effects & Healthline \\
\hline 6 & Health News Website & Vaccine side effects & Healthline \\
\hline 7 & AARP & Vaccine side effects & \\
\hline 8 & Medical organization & Vaccine side effects & Samaritan Health Services \\
\hline 9 & News organization & Vaccine side effects & BBC News \\
\hline 10 & News organization & Vaccine side effects & Spectrum News \\
\hline 11 & FDA & Vaccine FAQ \#1 & FDA Fact Sheet \\
\hline 12 & FDA & Vaccine FAQ \#2 & FDA Fact Sheet \\
\hline 13 & News organization & Vaccine side effects & CNBC \\
\hline 14 & General Media Outlet & Vaccine side effects & Nature Magazine \\
\hline 15 & Medical organization & Vaccine FAQ & Mayo Clinic \\
\hline 16 & Pharmaceutical & Vaccine roll out announcement & Johnson \& Johnson \\
\hline 17 & News organization & Vaccine side effects & Local news organization \\
\hline 18 & Industry think tank & Vaccine side effects & Kaiser Family Foundation \\
\hline 19 & News organization & Vaccine side effects & $\mathrm{CNN}$ \\
\hline 20 & State Government & Vaccine FAQ & Texas \\
\hline 21 & WHO & Vaccine immunity & \\
\hline 22 & Government & Vaccine side effects & Australia \\
\hline 23 & General Media Outlet & Vaccine side effects & Good Housekeeping \\
\hline 24 & Medical News organization & Vaccine information & UpToDate \\
\hline 25 & News organization & Vaccine side effects & Local news organization \\
\hline
\end{tabular}

Search conducted: March 3, 2021, 1430 CST 


\section{APPENDIX C}

Table 6 Additional social and insurance influences on vaccine administration

Dependent variable: Vaccines administered per 100k population [VACadmin]

\begin{tabular}{|c|c|c|c|c|c|c|}
\hline Model $\rightarrow$ & A. 1 & A. 2 & A. 3 & A. 4 & A. 5 & A. 6 \\
\hline \multicolumn{7}{|c|}{ Internet search information variable } \\
\hline Vaccine Availability & $7.37^{* *}$ & $6.28^{* *}$ & $7.98^{*}$ & & & \\
\hline [INTERNETsearchA] & $(2.3)$ & $(2.1)$ & $(2.2)$ & & & \\
\hline Vaccine Safety & & & & $379.60^{* *}$ & $345.92^{* *}$ & $394.90^{* *}$ \\
\hline [INTERNETsearchB] & & & & $(2.6)$ & $(2.3)$ & $(2.4)$ \\
\hline \multicolumn{7}{|c|}{ Other state-level control variables } \\
\hline State Per Capita GDP & 77.96 & 64.32 & 86.22 & $81.52^{* *}$ & $70.69^{*}$ & $83.63^{*}$ \\
\hline [GDPpc] & (1.6) & $(1.4)$ & $(1.5)$ & $(2.3)$ & $(1.9)$ & $(1.8)$ \\
\hline State Population & $-1,806.7^{* *}$ & $-1,895.1^{* *}$ & $-1,798.4^{* *}$ & $-867.7^{*}$ & $-1,016.7^{*}$ & -815.81 \\
\hline [StSIZE] & $(4.0)$ & $(4.0)$ & $(3.8)$ & $(1.8)$ & $(2.0)$ & $(1.5)$ \\
\hline $\begin{array}{l}\text { Percent of Population }>65 \\
\text { [ELDERLY] }\end{array}$ & $\begin{array}{l}42.05 \\
(0.2)\end{array}$ & $\begin{array}{l}-7.12 \\
(0.0)\end{array}$ & $\begin{array}{l}-123.88 \\
(0.5)\end{array}$ & $\begin{array}{l}183.15 \\
(1.0)\end{array}$ & $\begin{array}{l}133.11 \\
(0.7)\end{array}$ & $\begin{array}{l}221.44 \\
(1.1)\end{array}$ \\
\hline Rural Population & 52.31 & 79.03 & 24.15 & 29.42 & 52.18 & 10.44 \\
\hline [RURAL] & (1.3) & $(1.6)$ & $(0.8)$ & $(1.0)$ & $(1.1)$ & $(0.3)$ \\
\hline White population & $-3,733.6$ & & & $-2,504.9$ & & \\
\hline [RACE] & $(1.2)$ & & & $(0.9)$ & & \\
\hline Non-English language & & $110.10^{*}$ & & & 80.92 & \\
\hline [LANGUAGE] & & $(1.8)$ & & & $(1.1)$ & \\
\hline No health insurance & & & $12,960.3$ & & & $5,855.1$ \\
\hline [NOinsurance] & & & $(1.0)$ & & & $(0.5)$ \\
\hline Adj. R-square & 0.44 & 0.46 & 0.44 & 0.50 & 0.51 & 0.49 \\
\hline F-statistic & $5.99^{* *}$ & $6.08^{* *}$ & $5.27^{* *}$ & $5.76^{* *}$ & $5.74^{* *}$ & $5.68^{* *}$ \\
\hline Observations & 50 & 50 & 50 & 50 & 50 & 50 \\
\hline
\end{tabular}

Variable definitions are provided in Table 1. All models are estimated via ordinary least squares and include a constant term (not reported). The numbers in parentheses are robust (absolute value) t-statistics.

*denotes statistical significance at the $10 \%$ level; **denotes significance at the $5 \%$ level (or better)

\section{References}

Abdou AM (2021) Good governance and COVID-19: The digital bureaucracy to response the pandemic (Singapore as a model). J Public Aff. https://doi.org/10.1002/pa.2656

Alfano V, Ercolano S (2020) The efficacy of lockdown against COVID-19: A cross-country panel analysis. Appl Health Econ Health Policy. https://doi.org/10.1007/s40258-020-00596-3

Asongu SA, Diop S, Nnanna J (2020) The geography of the effectiveness and consequences of Covid-19 measures: Global evidence. J Public Aff. https://doi.org/10.1002/pa.2483

Baldwin R, Weder di Mauro B (eds) (2020) Economics in the Time of COVID-19. CEPR Press, Centre for Economic Policy Research, London

Bayram AB, Shields, T (2021) Who trusts the WHO? Heuristics and Americans' trust in the World Health Organization during the COVID-19 pandemic. Soc Sci Q. https://doi.org/10.1111/ssqu. 12977

Farzanegan MR, Feizi M, Gholipour HF (2020) Globalization and outbreak of COVID-19: An empirical analysis, CESifo working paper \#8315, May. https://www.cesifo.org/en/publikationen/2020/workingpaper/globalization-and-outbreak-covid-19-empirical-analysis 
Goel RK, Hsieh EW-T (2002) Internet growth and economic theory. Netnomics 4(2):221-225

Goel RK, Mazhar U, Saunoris JW (2020) Identifying the corrupt cog in the wheel: Dimensions of supply chain logistics and cross-country corruption. Aust Econ Pap. https://doi.org/10.1111/1467-8454. 12226

Goel RK, Nelson MA (2014) Whistleblower laws and exposed corruption in the United States. Appl Econ. 46(20):2331-2341

Goel RK, Nelson MA (2021) Drivers of COVID-19 vaccinations: Vaccine delivery and delivery efficiency in the United States. Netnomics, in press

Goel RK, Nelson MA, Naretta MA (2012) The internet as an indicator of corruption awareness. Eur J Polit Econ 28(1):64-75

Goel RK, Saunoris JW, Goel SS (2021) Supply chain performance and economic growth: The impact of COVID-19 disruptions. J Policy Mod 43(2):298-316

Kaur SP, Gupta V (2020) COVID-19 Vaccine: A comprehensive status report. Virus Res 288:198114. https://doi.org/10.1016/j.virusres.2020.198114

Persad G, Peek ME, Emanuel EJ (2020) Fairly prioritizing groups for access to COVID-19 vaccines. JAMA 324(16):1601-1602. https://doi.org/10.1001/jama.2020.18513

Potrafke N (2018) Government ideology and economic policy-making in the United States-A survey. Public Choice 174:145-207

Price G, van Holm E (2021) The effect of social distancing on the early spread of the novel coronavirus. Soc Sci Q. https://doi.org/10.1111/ssqu.12988

Yum S (2020) Social network analysis for coronavirus (COVID-19) in the United States. Soc Sci Q. https://doi.org/10.1111/ssqu.12808

Publisher's Note Springer Nature remains neutral with regard to jurisdictional claims in published maps and institutional affiliations. 